\title{
Trialling micro-learning design to increase engagement in online courses
}

\author{
Chris Kossen \\ University of Southern Queensland, Toowoomba, Australia, and \\ Chia-Yi Ooi \\ Wawasan Open University, Penang, Malaysia
}

\section{Effects of micro-learning design in \\ online courses}

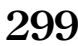

Received 6 October 2021

Revised 26 October 2021 27 October 2021

Accepted 28 October 2021

\begin{abstract}
Purpose - This paper reports on how micro-learning design principles are being trialled in an Australian and a Malaysian university to make online courses more accessible and attractive, and a more positive experience, with the aim of increasing student success. Central to this approach is segmenting materials into "bite-size" instalments by way of short micro-lecture presentations and reducing other content. The aim of this "less is more" strategy is to reduce unnecessary cognitive load as an impediment to learning so that focus can shift to prioritising the most essential skills and content. The purpose of this trial is to explore the efficacy of micro-learning as a means for increasing student engagement and learning.
\end{abstract}

Design/methodology/approach - The trials involved a mixed mode methodology drawing on qualitative and ratings data from course satisfaction surveys and records on grades and completion.

Findings - To date, results have shown significant increases in student engagement and satisfaction, and also performance. Our application of micro-learning included reducing volume of content based on its practical value, use of novelty (e.g. infusing guest presenter input) and design of practical and collaborative student activities.

Research limitations/implications - Early results are encouraging regarding apparent utility for engaging learners and ease of application, i.e. implementability and transference potential. However, the rapidly expanding area of online learning requires further research to establish a well-validated evidence base for effective online teaching practices.

Practical implications - The findings are relevant to universities involved in online and blended learning. Micro-learning design methods show promise in being able to address major engagement barriers including cognitive overload.

Social implications - More students are struggling with learning in today's social environment brought about with the massification of higher education. Micro-learning seeks to address major barriers these learners face with methods that go beyond traditional teaching practices.

Originality/value - Findings here are encouraging and contribute to existing understanding on ways to increase learner engagement in the competitive and fast-growing area of online learning for universities globally.

Keywords Micro-learning, Online learning, Online learning design, Online student engagement, Online learning delivery, Cognitive overload

Paper type Research paper

\section{Introduction}

Cognitive overload and the stress that it creates leave many learners with a sense of feeling "overwhelmed" by the volume of course materials. This has been identified as a major barrier

(c) Chris Kossen and Chia-Yi Ooi. Published in Asian Association of Open Universities Journal. Published by Emerald Publishing Limited. This article is published under the Creative Commons Attribution (CC BY 4.0) licence. Anyone may reproduce, distribute, translate and create derivative works of this article (for both commercial and non-commercial purposes), subject to full attribution to the original publication and authors. The full terms of this licence may be seen at http://creativecommons.org/licences/by/4.0/ legalcode

Funding: This study was funded by the Wawasan Open University's Centre for Research and Innovation (CeRI). The research project is funded from the 1st of November 2020 to 1st May 2022. The authors thank the committee of CeRI for providing the opportunity to carry out the research and knowledge sharing with this on-going research grant.

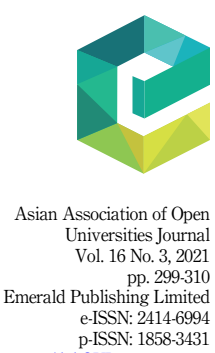


AAOUJ 16,3

\section{0}

to effective learning, and the confidence and motivation to engage. As such, it is a leading contributor to student attrition (Kamel, 2018). Cogitative overload and its associated stress is a barrier which micro-learning seeks to address (Gutierrez, 2018). This current trial (involving two separate trial between an Australian and Malaysian university) has involved the application of micro-learning design principles with the aim of making online course materials seem less daunting, more manageable and thereby more attractive to learners. Micro-learning design has been applied and trialled in selected courses by creating bite-sized (learning-chunked) materials. These include micro-lectures and short lecturer videos which include "how to" guides to assist learners to study the content more effectively and produce quality assignments. Novelty also featured in our design and delivery; for example, (1) using variety in voice, style and tone and (2) infusing short contributions by colleagues and guests, as ways to stimulate and sustain interest.

\section{Literature}

As online learning continues its rapid growth, it has opened new opportunities for making higher education accessible to many more people. It offers advantages of convenience and flexibility, features that are understandably promoted. However, it also carries increased risks and challenges, as online students are much more likely to drop out and not finish courses. Indeed, this era of massification of higher education, there are more students struggling than ever before. Micro-learning seeks to address cognitive overload as a major barrier facing many learners today (Korstange et al., 2020), by reducing information volume and making learning materials more attractive and engaging for students (Jomah et al., 2016; Kamel, 2018).

The term "micro-learning" was itself coined in 2005 by Research Studios Austria, where its essence was encapsulated as "learning in small steps". Gutierrez (2018) explains that "Micro-learning refers to an educational approach that offers bite-sized, small learning units with just the necessary amount of information to help learners achieve the goal." This "less is more" approach to engineering student learning experiences is increasingly seen as a way to optimise learning by making materials more manageable, more appealing and ultimately more engaging. A study by Dresden University found that the short bursts of content in micro-learning improved retention of information by $22 \%$ over traditional learning (Kapp et al., 2015). A study published in the Journal of Applied Psychology, reported that bite-sized chunks can increase efficiency and transfer of learning by $17 \%$ and more (Gutierrez, 2018). Bite-sizing is used to produce learning materials that they are more focussed and concise.

Ideally, the reduction process starts with the reviewing of course materials, including course learning objectives, for determining and prioritising content in terms of practical value and relevance, for example, value and relevance to assessments and professional work skills.

Making it instantly apparent to students that they can view, hear and read materials easily in small bite-sized segments, is also central to the design approach. This is based on a pedagogical strategy aimed at decreasing common "daunted by length" perceptions and the reactions students experience when they encounter learning materials (Jomah et al., 2016; Leary et al., 2020).

Micro-learning involves a more targeted approach to learning design in which unnecessarily redundant information is filtered out. This is to reduce cognitive load and the cluttering of working-memory with less relevant and extraneous information. By focusing only on small targeted "chunks" of vital information, absorption and retention becomes easier, thus making deep comprehension and application of knowledge more attainable. Support for this approach (i.e. designing optimal learning experiences to better equip learners to attain learning objectives) is substantial (Darby and Lang, 2019; Kamel, 2018; Kapp et al., 2015; Kapp and Defelice, 2019; Leary et al., 2020). 
The population profile of students today has also changed substantially as participation in higher education continues to increase, with many lower socio-economic students now studying. Many learners today have become accustomed to digital media, consuming shorter bursts of content and hence experience greater difficulty in maintaining focus for longer periods. Traditional methods, reading and memorising pages of material, are becoming increasingly less effective, and even more so in Open and Distance Learning (ODL). By designing and delivering content in small and very specific "bursts", micro-learning can help us engage better with, and meet the needs of contemporary learners (Buchem and Hamelmann, 2010; Jomah et al., 2016; Leary et al., 2020), who are at risk because they experience difficulty with traditional approaches, which are exacerbated in the world of "remote" online higher education. Micro-learning design has now emerged as an approach that enables academic teachers to engineer learning experiences in ways that increase the appeal of learning materials by reducing cognitive load and stress, as a well-established educational strategy for increasing information absorption and knowledge retention (Biggs, 2012; Sweller, 2010).

Cognitive load theory studies have also shown that people can process visuals 60,000 times faster than text and that people retain up to $95 \%$ of video messages compared with $10 \%$ when reading the text (Dunn, 2019; Skulmowski and Rey, 2018). Further to this, people's information preferences are also shifting rapidly towards visual and video over documents and web articles (Cisco, 2018; Forrester Research Report, 2014). Hence, micro-learning videos, in the form of video animated slide presentations and personable lecturer guidance and encouragement videos, feature as core instructional tools for engaging students in learning. Providing learners with short, segmented and scaffolded instalments of information increases retention and mastery of key and threshold concepts (Gutierrez, 2018). A critical element underpinning micro-learning design and delivery is clear communication which includes providing explicit explanations throughout each stage of the learning journey. For example, clearly explaining the purpose and objectives of a lesson or reading and its value (e.g. for professional employability and for doing well in assessments).

\section{Trial one University of Southern Queensland (USQ)}

As a successful public relations and communication educator at the University of Southern Queensland (USQ), Australia, I, Chris Kossen, first author, teach communication skills, with a commitment to the effectiveness of my own communication as a teacher.

I have long maintained favourable teaching performance metrics, evidenced through student feedback, student performance and completion rates. However, in 2017, I noted a few students commented that at times they felt daunted by the length of materials in modules, readings and some lectures. It then seemed reasonable to assume that other students would also be experiencing this.

Upon reviewing educational literature, I found that cognitive overload and stress leading to a sense of being overwhelmed by volume in learning materials had been identified as a major barrier to effective learning and motivation to engage, especially for students entering university (Kamel, 2018; Sweller, 2010; Whitehead, 1949). Reflecting on this I decided to address the issue by focusing on making materials less daunting and more appealing to learners, i.e. more "student-friendly". Hence, I began adopting micro-learning design principles to reduce volume in learning materials with the aim of improving student experience, increasing motivation to engage and communicating content and skills more effectively.

Micro-learning is a pedagogical approach which seeks to address cognitive overload by providing small "bite-sized" learning units where information is reduced and focused primarily on the most relevant concepts and skills (Gutierrez, 2018). By digesting only small "chunks" of vital information, absorption, comprehension and memory

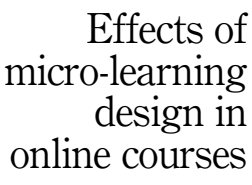

301 
AAOUJ 16,3

\section{2}

retention become more manageable and threshold learning less cognitively demanding. Ultimately, this makes the attainment of learning objectives more achievable (Kamel, 2018; Sweller, 2010).

\section{Trial one: application}

Key elements in the application and implementation of micro-learning involved:

(1) Shortening length of modules (increasing modules to one-per-week, e.g. splitting long modules): Reduced reading load (e.g. editing out unnecessary pages), increased visuals, graphics, audio and reduced text (e.g. sourcing shorter videos);

(2) Miro-cast slide presentations: 2-3 per week, $7-15$ min each (in place of single $50 \mathrm{~min}$ ), inclusion of activities, exercises and 3-4-min audio-casts, i.e. podcasts;

(3) Dynamic voicing with co-presenters: e.g. colleagues, guest speakers (with minimal demand requirements) as vocal dynamism to break the monotony of one voice and one perspective;

(4) Lecture-presence videos: 1-2 min video guides for each module to personalise delivery, boost dynamics and "sell" engagement in the week's materials (e.g. readings, videos), lecturer video guides for each assessment (3-4 min);

(5) Relevance linking: Frequent linking of the relevance of content to assessments and employment (i.e. professional practice, work tasks and skills).

My success in teaching had long been underpinned by regular emphasis on relevance, through building practicality into class activities linked to work-based tasks and scenarios, along with discussion questions which enabled students to explore relevancy of concepts and principles from their own life perspective. I have long found that reducing content and structuring it according to its usefulness to students for producing quality assessments and identifying value and practicality for employment and work performance are effective ways to determine and focus materials. In this respect, my existing approaches already had a natural and logical fit with micro-learning.

Furthermore, in applying "less is more" reduction principles, it is important to keep presentation slides brief, uncluttered, direct and "to-the-point". These design principles then continue through to readings and video learning materials. Micro-learning design requires focusing on the reviewing of content in order to determine and prioritise content as the key to reducing volume. The relevance and value of reading materials should also be highlighted in micro-lectures. Otherwise, their continued inclusion should be reconsidered.

Also important is making it immediately apparent to students upon entering the Course Portal (Moodle) that they can easily view, listen or read materials in compact bite-sized segments. This serves as a way to decrease "volume shock". Evaluation feedback data showed that many students found content presented in this way easier to navigate, and the readily accessible micro-sized lecture videos helped them better manage their learning, i.e. at their own pace, at times when they felt ready and motivated to engage in periods of study.

\section{Trial one: results}

Student performance in assessment, along with learning management system (LMS) course engagement analytics and student feedback (course evaluation and satisfaction ratings) to date indicate support for this "less is more" approach as an effective way to optimise learning 
materials by making them more manageable and hence engaging. Again, the efficacy of bitesizing approaches is well supported in published literature (Gutierrez, 2018; Jomah et al., 2016; Kamel, 2018; Kapp and Defelice, 2019) (see Tables 1 and 2).

USQ Student Feedback Survey.

\section{Effects of micro-learning design in \\ online courses}

303

Table 1.

Public relations research methods
Student satisfaction (five-point scale)

Trend: increased completion
2017

2017
$4.3 \quad 2018$

$79 \% \quad 2018$
Year/Results

$4.8 \quad 2019$

$88 \% \quad 2019$

$\begin{array}{ccc}4.8 & 2020 & 4.8 \\ 96 \% & 2020 & 90 \%\end{array}$

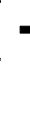

Year/Results

\begin{tabular}{lcccccc}
\hline Student satisfaction (five-point scale) & 2018 & 4.2 & 2019 & 4.6 & 2020 & 4.7 \\
Trend: Increased completion & 2018 & $81 \%$ & 2019 & $92 \%$ & 2020 & $97 \%$
\end{tabular}

Table 2.

Community consultation and development

I loved the short lectures. It made studying with kids at home a lot easier . . . I could squeeze them in wherever I could and did not have to dedicate hours that I did not have.

The way PowerPoints contained audio clips was fantastic.

Mini-presentations for online students were really helpful and assisted me with interpreting information in a way that helped me better understand material.

Micro lectures are to the point and helped focus learning.

Other Faculties need to look at what you're doing here and learn from this.

The way this class is done online should be the standard. Easy to navigate, sectioned into modules, everything is very easy to access including the mini-lectures and Zoom classes which were put online.

Data thus far, as shown above, provide encouraging support for micro-learning design approaches as adopted for this trial. Since its adoption, completion rates have increased for students enrolling in these two courses selected for micro-learning design, Public Relations Research Methods (from 2018 onwards) and Community Consultation and Development (from 2019 onwards).

Student satisfaction ratings from independently conducted university course surveys have increased to a very high range of 4.7-4.8 (based on a five-point rating scale). Student comments from the survey data lend important qualitative support point to the use of microlearning design as making learning noticeably more manageable and enjoyable for students studying these courses.

\section{Trail two (Wawasan Open University (WOU)) in progress}

The purpose of Trial Two also included transference. Transferring knowledge and experience from the first trial in an Australian to a Malaysian university. Hence, the trialling microlearning here is to learn, adapt and apply the micro-learning design principles for USQ courses, starting with the re-designing of the content and delivery of a selected General Studies course, MPU3333/03 Human Rights. The General Studies or MPU (Mata Pelajaran Umum) course is compulsory for undergraduate degree programmes in Malaysia. This project (trial) is a 
AAOUJ 16,3

\section{4}

collaboration with USQ, Australia, where transference of knowledge on micro-learning gained from trialling micro-learning design is being shared and transferred.

The key aim is to develop a prototype of a standardised format for utilising micro-learning design to structure the content of courses into manageable "chunks" to help improve student engagement, their learning experience and performance. The first objective was to convert Human Rights courses to fully online courses in order to trial and evaluate micro-learning principles. The second objective was to develop and conduct workshops to train and equip Wawasan Open University (WOU) staff with skills and knowledge for adopting and applying micro-learning design more widely, based on trial results.

\section{Context, literature and development of problem statement}

As in Trial One, we recognised that student cognitive overload is often overlooked as a barrier to academic performance and achieving good grades. Also, the consequences are serious, leaving many learners feeling overwhelmed, bewildered and helpless in the face of needing to meet academic requirements for success in their university studies. This is even more so for ODL learners who are studying part-time while working full time. And once again, it has long been known that many students experience difficulty in managing the academic workload at university (Bitzer and Troskie-De Bruin, 2004).

A student's perceptions of the demands of academic tasks along with perceptions of their ability to succeed in those tasks, i.e. their level of self-confidence, influences levels of effort and engagement in set tasks. Lower levels of confidence can lead to higher non-completion and attrition (Petersen et al., 2011). Accordingly, a decision was made to trial micro-learning principles to address confidence and cognitive load barriers by segmenting and scaffolding materials, and by the use of guidance-based videos for breaking assignments into smaller and more manageable subtasks.

\section{Trial two: research aim}

The aim in this phase of the research is to explore the efficacy of micro-learning design for:

(1) improving student experience, engagement and perceptions of learning; and

(2) to explore and trial implementability.

All research here is being conducted with institutional approval and in accordance with appropriate ethical requirements for this project.

\section{Trial two: project plan and progress}

Stage 1 - Review of content. The first selected prototype course, MPU3333/03, is Human Rights, a level 100 compulsory course in the Bachelor of Liberal Studies (Hons). Course content was first reviewed and reduced, and scripting for the videos and micro-presentations was then developed. Stage 2-Producing videos for pilot course. Materials in the form of animated videos are now being produced, to be uploaded to LMS: Moodle (Brightspace) and will include a welcome video, assignment guide videos, module summary videos and short podcasts as the primary learning elements for the Human Rights course.

Stage 3 - Feedback and data analysis. Student sampling is to include all students enrolled in the Human Rights course from all five regional centres. A mixed mode methodology is being adopted with institutional student feedback surveys and group interviews, followed by data analysis.

Stage 4-Final report. The final stage will be completion of the final report on the findings of the research. The prototype course will also be adapted and used for the purpose of training workshops for lecturing staff in an effort to increase uptake of micro-learning design. 
Micro lectures made it easier to understand the lessons, and it was much less boring.

I liked the style, the clear explanations.

Videos were short and sweet, with really easy-to-understand explanations and examples. Also, easy to view again anytime.

Lecturer videos were really useful for showing how key points are relevant to the assignments.

Having videos is much easier and better compared to having PDF readings only.

I found it [micro format] very useful ... gives me more understanding and more quickly.

Having the questions and activities included helped me learn better.

Now it is easier to understand the modules, the video lectures are awesome and helpful for students because we can replay.

Video lectures gave me a clear picture for my learning and made me feel more connected to the lessons. Now it's not so boring for me to study.

Micro videos are quick, direct and to the point. They gave me good insights into how to complete my assignments, and also helped me save time.

While these data results are only early, they are encouraging in providing support for the efficacy of micro-learning design in reducing cognitive overload and stress. Indicators of stress reduction within this student feedback data set are apparent in comments like: "it is easier to understand", "easy-to-understand explanations and examples" and "easy to view again anytime". Indicators of increased engagement are apparent in comments like: "much less boring" and "having the questions and activities included helped me learn better".

Preliminary tutor feedback thus far also helped affirm the efficacy of micro-learning in this trial:

The micro learning resources assisted me greatly in preparing and running my tutorial sessions in a more focused way. (Tutor 1)

Having the recorded micro-lectures gave me a clearer direction and benchmark for being able to tutor my students. Having the activities and discussion questions was really useful too. (Tutor 2)

To date, the "implementability" of micro-learning, in other words, the adopting of the design methods in this Malaysian phase of the trial, has not been overly difficult or arduous. For example, scripting content for guest presenters was relatively simple and not time intensive. Likewise, the demands placed on these presenters were minimal. Early indications point to micro-learning design as being implementable without large expenditure required.

\section{Discussion: application of micro-learning design}

Using a constructivist approach, micro-learning seeks to build knowledge and skills incrementally with a series of short segments of clear and focused information combined with embedded performance enabling activities. These singular micro-learning events fit together as a part of a wider whole in a process known as "scaffolding". The harder the conceptual material becomes, the greater the amount of scaffolding that is required to ensure effective learning. For instance, an increased number of shorter duration lessons are required, with more repetition and more frequent practice-based activities that also include feedback and appraisal of those activities. Connecting new content or information to prior content (existing 
AAOUJ 16,3

\section{6}

Figure 1.

PowerPoint slide knowledge) plays a critical role in design because it helps ensure transfer from working memory to long-term memory (Kapp and Defelice, 2019; Sweller, 2010).

Having audio-visual at the centre of delivery, i.e. making learning primarily an audiovisual experience, and the key entry point, appeared to be effective in making content more attractive to students and in stimulating, as well as sustaining interest and engagement. Micro-lectures can include a mix of live in-class and home (or office) voiced recorded slides. We have used audio-visual delivery, micro-presentations and lecturer videos, to serve as a vehicle for creating interest and curiosity by using them to "sell" the rewards and benefits students can gain by understanding the set content, e.g. concepts, principles, theories and case studies. This "stimulating interest" strategy has become a feature in our approach and is based on "relevance-linking" which again involves explicitly drawing attention to the practical value and benefits students can gain from the topics and concepts to be covered.

Again, relevance is often linked through explaining and demonstrating the usefulness of knowledge/content and skills to employment and performing well in assessments. This then also includes building in active application experiences and opportunities for students through activities and exercises. For example, first year students commence their first assessment, an essay, in their very first class, which is a micro-lecture which incorporates a tutorial type activity. The key topics for their first micro-lecture are ethics and professionalism.

Figure 1 shows how a practical assignment-preparation activity, based on the lecture topic area, was embedded in a PowerPoint slide. The purpose of this activity is to engage students in the starting of their first assignment in their very first class. Students are tasked with writing the first sentence of their essay, namely, a thesis statement, as the focus point for their entire essay. They are then asked to identify one or two potential main supporting points which they select from the points just presented in their first lecture.

An assessment-linked activity as shown in Figure 1 is designed to make students aware that keeping the assignments that they have been set firmly in mind is an effective and efficient way for them to process the content they are encountering, especially in leading up to the submission date of an assignment. It helps better guide learners on how to focus on the learning resources they are being provided in their courses.

This trialling of micro-learning has also shown that active learning engagement, as traditionally associated with on-campus classrooms, can transfer into online presentations and classes. Basing online classes on collaborative learning by making them primarily activity-based proved to be an effective means for engaging students in both content and skills learning through participation. This is based on a constructivist-centred approach that believes learning is most effective when students are able to construct their own knowledge 
and understanding through active engagement with principles and concepts (using activities) (Steffe and Gale, 2012). Learning activities can be designed to develop their understanding of new concepts by asking them to consider how these concepts relate to their own life experiences, and also how they relate to existing knowledge learned from earlier classes. This can also extend into discussions about their understandings of the practical value of the concepts and ideas they are studying. Our role as learning facilitators, today more than ever, is to provide learners with the encouragement and guidance so many of them now need to be able to learn effectively and to make that experience a rewarding one for them.

In online classes, I (first author) physically type key points extracted from student responses as they occur during class time so that their responses are made visible using the "share screen" facility which is available with online video conferencing platforms. Student feedback and data in relation to this, including student comments below, show encouraging acknowledgement of the efficacy of this collaborative and interactive approach to constructing knowledge and understanding synchronously (i.e. in real time). Thus far it appears to have worked well as a way to affirm and encourage learners about the value of their involvement and input. In the case of this study, it also enabled learners to develop a sense of belonging and sense of community. Notably, the overall results of this trial provide support for idea that the rich engagement and interactivity, typically associated with campus classroom teaching, can be successfully transferred into online environments.

\section{Recent results : USQ 2020 student course satisfaction survey}

This is the best course I have studied so far, especially because the classes for online students allowed us to enjoy "learning by doing" interesting activities that are practical and useful.

[I liked] being able to discuss course materials and working with the other students on activities.

[As students] we are treated with respect and encouragement.

We are made to feel relaxed and able to contribute openly in [online] classes.

In addition to linking practical value relevance to professional employment and assessments, criteria for selecting and creating engaging activities can include: (1) authentic design, e.g. highly relevant case studies, scenarios, problems; (2) novelty, e.g. interest provoking scenarios and discussion questions and (3) opportunities for enjoyment and satisfaction through achievement, e.g. gamification. However, this need not be confined to electronic "game" forms. But it is important that activities are also embedded in micro-lectures, and not only in online classes.

As stated earlier, a key feature underpinning micro-learning design is clear communication with explicit explanations throughout. Accordingly, the purpose of a learning activity should be explained along with the value it is meant to provide. Further to this, its value should be pitched to learners, to help ensure an activity works well and serves its purpose. In other words, we should prompt student interest, and try to get them motivated. This also requires providing them with a welcoming environment by giving students a genuine sense of ownership and belonging, becoming "students as partners" in learning activity sessions. These high-engagement design features in micro-learning are aimed at involving students in deep level learning to help develop retention of knowledge and skills as well as advanced mastery and understanding (Biggs, 2012; Kapp and Defelice, 2019).

\section{Continuing development and implications for research and practice}

The application of micro-learning design principles thus far has involved the use of trial and error for the purpose of continuous improvement, e.g. increasing vibrancy through novelty,

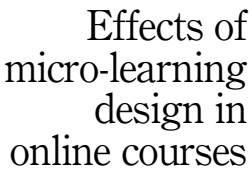

307 
AAOUJ 16,3

namely dynamic variance. With experimentation we discovered that students find microlectures especially relatable when a conversational style is used. Further to this, varying formal and informal styles also works effectively as a way to increase impact. To date, we have learned that providing colleagues with a script they can work from for voicing slides can be an efficient and effective way to achieve desired impact, while at the same time keeping demands on contributors minimal. And the simple recording and reduction-editing skills which are helpful for micro-sizing (i.e. editing down), can be acquired easily. Engagement strategies of relevance-linking, especially explaining and demonstrating the usefulness of knowledge/content and skills for employment and for performing well in assessments, have proved effective in these trials. Active-engagement learning activities, where learners actively participate and collaborate in constructing their understandings, have also been effective. Further testing, development and refinement of all the elements applied in our trialling of micro-learning are continuing.

In terms of continued development of online teaching practice, we agree with the views of Darby and Lang (2019) that as practitioners of teaching and learning we are best served by using an approach of incrementally building our own levels of confidence in developing and improving capacities for online teaching. As individuals we also need to encourage our peers, near and far, to engage and put their faith in incremental development as an alternative to being overwhelmed by the pressure to become an outstanding online lecturer in a very short period of time. It is easy to see how this logic fits neatly with the principles of micro-learning itself with its segmented "breaking into smaller units" and scaffold building approach. Taking an incremental approach is also more likely to be sustainable and is necessary for keeping abreast of continuing change and development. Publishing teaching research and practice will also continue to play a major role in information exchange on the development of online teaching practice.

Early results emerging from this study are encouraging in showing that the energy of classroom learning and interaction is transferrable to online learning. This study has also helped to show that online learning can bring an array of advantages. As Darby and Lang (2019) note, online classes can provide better opportunities for having every student present involved in discussion - i.e. for having every voice heard.

We need to make education an engaging experience for learners at the grassroots level of course design and then also make lessons short and dynamic, as well as promoting class interactions if we want to increase their chances of being successful. Our success in this regard is tied to their success, especially over the long term. However, it is also important that we acknowledge and accept that substantial numbers of online students have chosen online as a study preference because it does not require attendance at classes. In this trialling of micro-learning, many of the non-attending students demonstrated, nonetheless, high levels of engagement which was as evidenced in performance on assessments. These early indications suggest that substantial numbers of these learners were benefiting from being able to view recordings of interactive online classes, as this was explicitly revealed in their responses in assessments. This, somewhat surprising outcome, suggests teaching practitioners look widely when thinking about and looking for indicators that may be useful for gauging student engagement.

\section{Conclusion}

Global and national trends are influencing the way that universities engage with students in the face of growing competition. Increasingly, competitors are starting to offer educational services through lower cost, online-only courses. In this context, micro-learning course design may provide universities with a valuable opportunity to offer time-poor students with affordable but accessible learning experiences that are attractive and engaging, and tailored 
to their needs, as a point of competitive advantage. Early results from this ongoing study, on micro-learning design principles, are encouraging in terms of their utility for engaging learners and relative ease of application, i.e. their implementability and transference potential. Thus far, results also provide support for the value of incorporating novelty into online learning design as a strategy for engaging and energising students and lifting their learning performance.

\section{Effects of micro-learning design in online courses}

\section{References}

Biggs, J.B. (2012), "What the student does: teaching for enhanced learning", Higher Education Research and Development, Vol. 31 No. 1, pp. 39-55.

Bitzer, E. and Troskie-De Bruin, C. (2004), "The effect of factors related to prior schooling on student persistence in higher education”, South African Journal of Education, Vol. 24, pp. 119-125.

Buchem, I. and Hamelmann, H. (2010), "Microlearning: a strategy for ongoing professional development”, eLearning Papers, Vol. 1 No. 21, pp. 1887-1542, available at: www. elearningpapers.eu.

Cisco (2018), White paper, available at: https://www.cisco.com/c/en/us/solutions/collateral/executiveperspectives/annual-internet-report/white-paper-c11-741490.html.

Darby, F. and Lang, J.M. (2019), Small Teaching Online: Applying Learning Science in Online Classes, Jossey-Bass and Pfeiffer, San Francisco, California.

Dunn, M. (2019), Research: Is a Picture Worth 1,000 Words or 60,000 Words in Marketing?, available at: https://www.emailaudience.com/research-picture-worth-1000-words-marketing/.

Forrester Report (2014), available at: https:/www.forrester.com/report/Improve+Customer+Engage ment+With+A+Blended+Learning+Strategy/-/E-RES115865\#figure3.

Gutierrez, K. (2018), Numbers Don't Lie: Why Microlearning Is Better for Your Learners (And You Too), available at: https://www.shiftelearning.com/blog/numbers-dont-lie-why-bite-sizedlearning-is-better-for-your-learners-and-you-too.

Jomah, O., Masoud, A.K., Kishore, X.P. and Sagaya, A. (2016), "Micro learning: a modernised education system”, Broad Research in Artificial Intelligence and Neroscience, Vol. 7 No. 1, pp. 103-110.

Kamel, O.M. (2018), "Academic overload, self-efficacy and perceived social support as predictors of academic adjustment among first year university students", International Journal of PsychoEducational Sciences, Vol. 7 No. 1, pp. 86-93.

Kapp, K.M. and Defelice, R.A. (2019), Microlearning: Short and Sweet, American Society for Training and Development, Alexandria, Virginia.

Kapp, F., Proske, A., Narciss, S. and Körndle, H. (2015), "Distributing vs. blocking learning questions in a web-based learning environment", Journal of Educational Computing Research, Vol. 51 No. 4, pp. 397-416.

Korstange, R., Hall, J., Holcomb, J. and Jasmeial, J. (2020), "The online first-year experience: defining and illustrating a new reality", Adult Learning, Vol. 31 No. 3, pp. 95-108.

Leary, H., Dopp, C., Turley, C., Cheney, M., Simmons, Z., Graham, C.R. and Hatch, R. (2020), "Professional development for online teaching: a literature review", Online Learning, Vol. 24 No. 4, pp. 254-275.

Petersen, I., Louw, J. and Dumont, D. (2011), "Adjustment to university and academic performance among disadvantaged students, South Africa”, Educational Psychology, Vol. 29 No. 1, pp. 99-115.

Research Studios Austria (2005), available at: https://kmeducationhub.de/research-studios-austria/.

Skulmowski, A. and Rey, G.D. (2018), "Embodied learning: introducing a taxonomy based on bodily engagement and task integration", Cognitive Research: Principles and Implications, Vol. 3 No. 1 , pp. 1-10. 
AAOUJ

AAOU

310
Steffe, L.P. and Gale, J. (2012), Constructivism in Education, Routledge, Oxon.

Sweller, J. (2010), "Cognitive load theory: recent theoretical advances", in Plass, J.L., Moreno, R. and Brünken, R. (Eds), Cognitive Load Theory, Cambridge University Press, Cambridge, pp. 29-47.

Whitehead, A.N. (1949), The Aims of Education: And Other Essays, New American Library, New York, NY.

\section{Corresponding author}

Chris Kossen can be contacted at: kossen@usq.edu.au

For instructions on how to order reprints of this article, please visit our website: www.emeraldgrouppublishing.com/licensing/reprints.htm Or contact us for further details: permissions@emeraldinsight.com 